\title{
Polyostotic Paget's Bone Disease. A Case Depicting a Rare Mandible Lesion Location
}

\author{
Vasilios Thomaidis, Anastasios Vasilopoulos, Gregory Tsoucalas* and Aliki Fiska \\ Department of Anatomy, School of Medicine, Democritus University of Thrace, Alexandroupolis, Greece \\ *Corresponding author: Gregory Tsoucalas, Ierolochiton 155, 38334 PC, Volos, Democritus University of Thrace, Greece
}

\begin{tabular}{|c|c|}
\hline ARTICLE INFO & ABSTRACT \\
\hline Received: April 13, 2019 & Paget's bone disease (PBD) is a nonmalignant, chronic focal metabolic bone disease \\
\hline Published: 慧 April 22, 2019 & $\begin{array}{l}\text { characterized by abnormal bone remodeling. It is more common in patients older than } \\
\text { fifty years old with a prevalence of } 2-4 \% \text { and a male to female ratio of } 1.8 / 1 \text {. It may affect }\end{array}$ \\
\hline $\begin{array}{l}\text { Citation: Thomaidis V, Vasilopoulos } \\
\text { A, Tsoucalas G*, Fiska A. Polyostotic } \\
\text { Paget's Bone Disease. A Case Depict- } \\
\text { ing a Rare Mandible Lesion Location. }\end{array}$ & $\begin{array}{l}\text { a single bone (monostotic) or multiple bones (polyostotic). It is mainly asymptomatic } \\
\text { and thus is usually diagnosed as an incidental finding. The exact cause of the PBD } \\
\text { remains obscure. However, it is easily diagnosed and effectively treated. In this short } \\
\text { communication we present a case of a 51-year-old female patient with an asymptomatic } \\
\text { polyostotic PBD. }\end{array}$ \\
\hline
\end{tabular}

Keywords: Pager Disease; Metabolic; Polyostotic; Panoramic X-Ray

Abbreviations: PBD: Paget Bone Disease; ALP: The alkaline phosphatase

\section{Introduction}

Paget's bone disease (PBD) is a focal, progressive metabolic bone disease of unknown etiology, characterized by abnormal bone resorption and deposition. It was firstly described in 1876 by Sir James Paget [1-2]. PBD may involve a single bone (monostotic) or multiple bones (polyostotic) [3]. PBD affects usually older patients and is more frequent in male individuals with a male to female ratio of $1.8 / 1$ and a prevalence of $2-4 \%$ to patients older than fifty years of age. On the other hand, it is rarely encountered to patients younger than this age [1]. The disease is more common in European population [1-2], followed by Australia, New Zealand and North America populations. It is an uncommon pathological entity in Scandinavian countries, Africa and Asia $[1,4]$. We present a case of a PBD found incidentally during a routine checkup.

\section{Case Report}

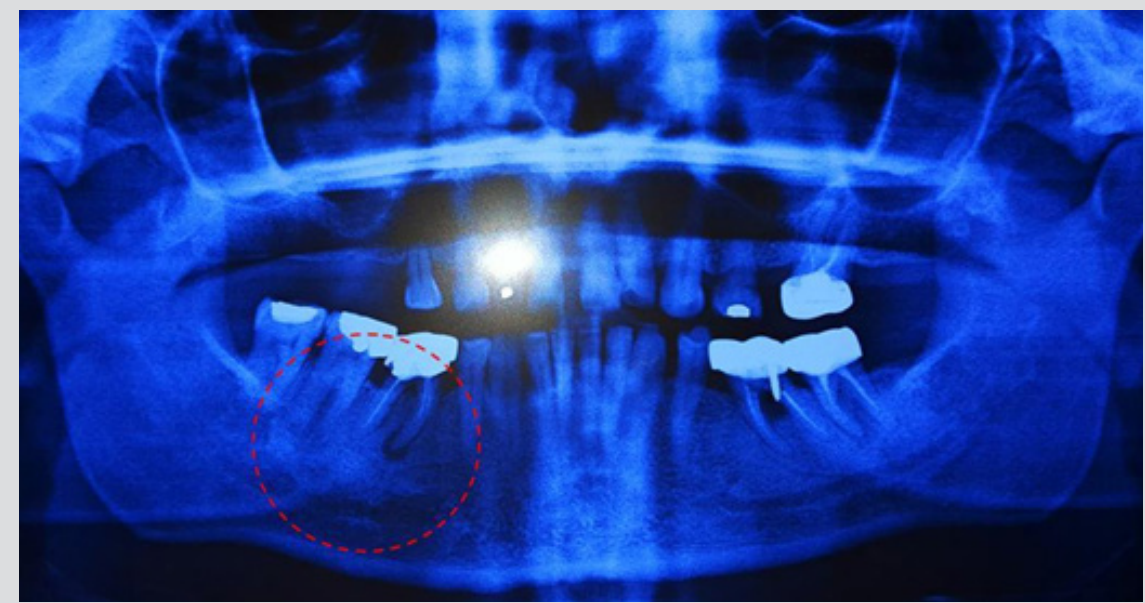

Figure 1: Panoramic radiograph. Hypercementosis of the teeth roots (red circle). 


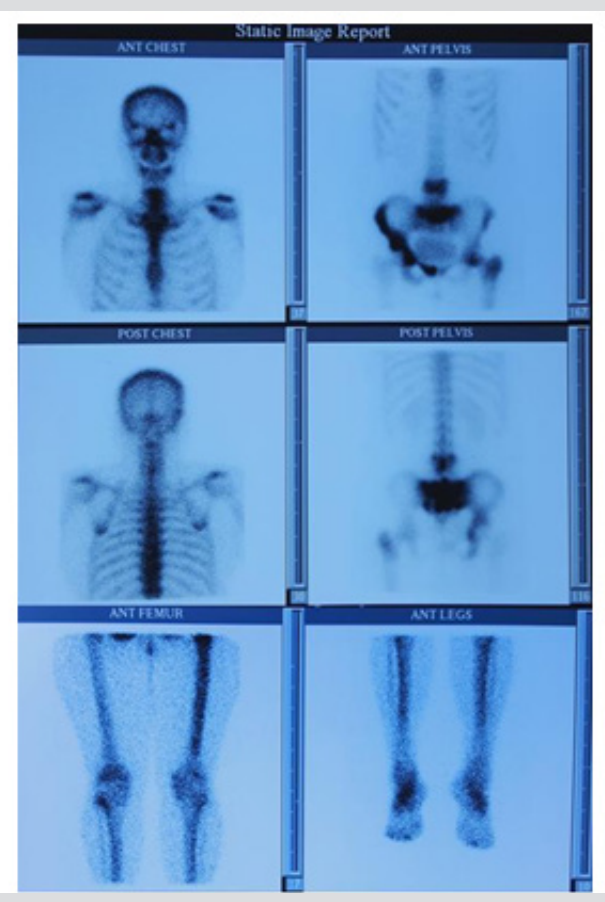

Figure 2: Bone scintigraphy showing increased radionuclide uptake at the fourth and fifth lumbar vertebrae, the sacrum, the sacroiliac joints bilaterally, the pelvis bones and the left femoral bone.

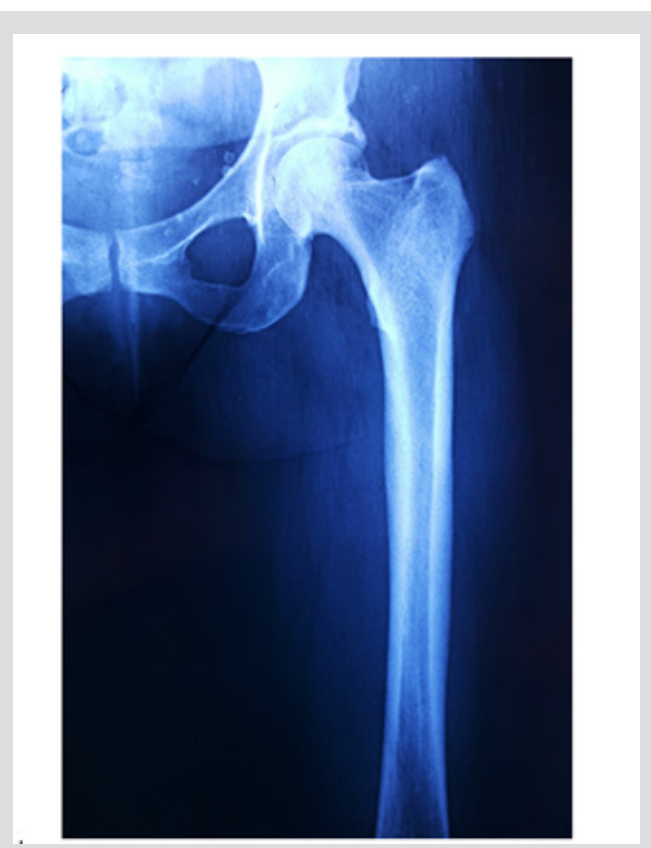

Figure 3: Left femur X-Ray. Abnormal thickening of the bone cortex.

A51-year-old female patient reported to an oral and maxillofacial practice in Alexandroupolis for a routine cluster of examinations. The panoramic radiography revealed hypercementosis of the teeth roots (rare finding) with no prominent chin region or a symmetric enlargement of the jaw (Figure 1). Paget bone disease was suspected, and so a bone scintigraphy was ordered. Bone scintigraphy was conducted under a $\gamma$-camera using the radionuclide Tc-99m, showing increased radionuclide uptake at the fourth and fifth lumbar vertebrae, the sacrum, the sacroiliac joints bilaterally, the pelvis bones and the left femoral bone (Figure 2). An $\mathrm{x}$-ray of the left femoral bone was also conducted, where thickening of the bone cortex was found (Figure 3). The alkaline phosphatase (ALP) enzymes levels were abnormally increased, measuring 299 U/l compared to the normal values of 20-130 U/l, while the SGOT and SGPT transaminase levels remained normal. Although patient reported no pain or other symptoms, a diagnosis for a polyostotic Paget's disease based on the radiographic, bone scintigraphy and biochemical findings was made.

\section{Discussion}

The pathogenesis of PBD is still unknown. Increased osteoclastic activity is seen on the affected regions, followed by abnormal bone deposition, resulting in a disarranged bone architecture with reduced durability. The most common theory suggests an interaction of genetic, viral and environmental factors [1-2]. The bones typically involved in PBD include the pelvis, the spine, both femora and the bones of the skull, but PBD may be observed to any other skeletal region $[2,4]$. The disease is mainly asymptomatic and is being diagnosed mostly incidental during routine radiographs or due to an elevated serum level of the alkaline phosphatase (ALP) enzyme. Symptomatic patients complain mainly about pain. Bone deformities or fractures may also be present at the time of the diagnosis [2]. PBD is accompanied with a plethora of complications; produced by the abnormal bone remodeling, including permanent hear loss, dementia, headaches, spinal canal stenosis, paraplegia, obstructive hydrocephalus and cranial neuropathy $[2,4]$.

Diagnosis is made after considering the clinical features, the radiographic images and the biochemical blood reports. X-Rays are important for diagnosing PBD. A decrease of bone density may be revealed as a result of the elevated osteoclastic activity, which may coexist with sclerotic lesions. Bone scintigraphy is also important to clarify the total extend of the disease [2]. The biochemical marker recommended in clinical practice is the total serum ALP, combined with liver function tests. The preferred treatment of PBD is the the application of anti-resorptive drugs such as bisphosphonates, such as alendronate $[2,4]$. Nuclear medicine bone scintigraphy evaluates physiology on a molecular level, thus providing an earlier detection of bone lesions before morphologic change is evident. Bone scans detect PBD earlier than radiographs and computed tomography. PDB very rarely affects the mandible. A further progrees of the PBD could cause deformation of the affected osseous region of the mandible, resulting to severe esthetic or prosthetic problems. Due to the fact that some reports provide evidence of PDB associated with other diseases arising in the affected region that cause additional burden to the patients such as osteomyelitis of jaws, osteosarcoma, tumours with prominent giant cells, hyperparathyroidism, and resorption of teeth [5], a continuous monitor of the patient was suggested. A biopsy of the bone is characterized by unique histological features and sometimes necessary to confirm the diagnosis, especially in cases with rare depictions of the disease [5]. 


\section{Conclusion}

A polyostotic PDB, including lesions of the jaw may result in bone deformities, fractures and symmetrical overgrowth of the entire mandible. Overgrowth of the bone appears to compensate for reduced fracture toughness. Diagnoses may usually be suspected by clinical examinations. An acute drug administration and a regular follow-up are advised.

\section{References}

1. De Oliveira FAK, Pinto FFE, Sardenberg T, Pereira GJC, Curcelli EC, Penna V (2019) Diagnosis and management of Paget's disease of bone- series of 8 cases. Acta Ortop Bras 27(1): 31-32.

\section{ISSN: 2574-1241}

DOI: 10.26717/BJSTR.2019.17.002971

Gregory Tsoucalas. Biomed J Sci \& Tech Res

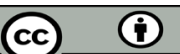

This work is licensed under Creative Commons Attribution 4.0 License

Submission Link: https://biomedres.us/submit-manuscript.php
2. Appelman Dijkstra NM, Papapoulos SE (2018) Paget's disease of bone. Best Pract Res Clin Endocrinol Metab 32(5): 657-668.

3. Karunakaran K, Murugesan P, Rajeshwar G, Babu S (2012) Paget's disease of the mandible. J Oral Maxillofac Pathol 16(1): 107-109.

4. Ralston SH, Corral Gudino L, Cooper C, Francis RM, Fraser WD, et al. (2019) Diagnosis and Management of Paget's Disease of Bone in Adults: A Clinical Guideline. J Bone Miner Res, pp. 3657.

5. Friedrich RE, Luebke AM, Amling M, Koehne T (2018) Clinical and Microstructural Findings in Paget Disease of the Entire Mandible. J Oral Maxillofac Surg 76(2): 336-346.

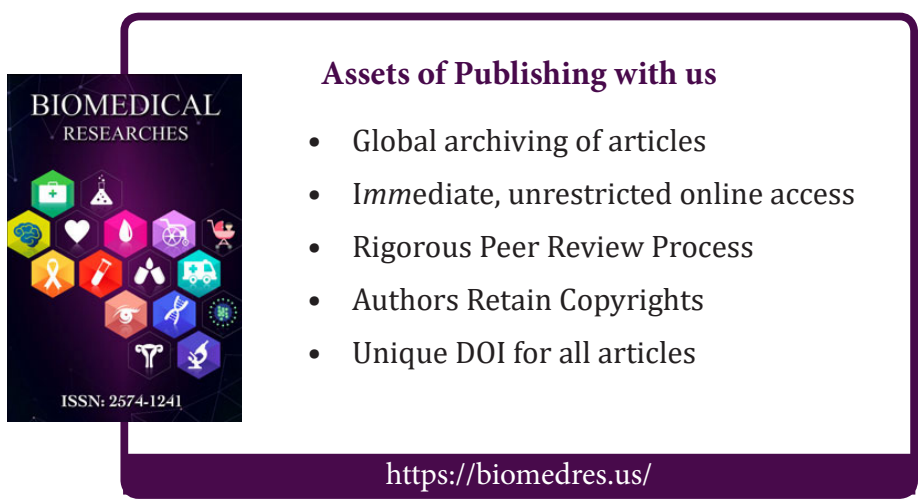

